\title{
Application of modern technological means in the process of digitization of models of national and historical value
}

\author{
Ginka Jecheva ${ }^{1}$, Tihomir Dovramadjiev ${ }^{1}$, Momchil Tachev $^{1}$ and Kremena Cankova ${ }^{1}$ \\ 1-Technical University of Varna, Department of Industrial Design, 9010, 1 Studentska Street, Varna, Bulgaria
}

Corresponding author contact: ginkaaltu-varna.bg

\begin{abstract}
Bulgaria has been known for its rich history since ancient times. Within its current territory, the country encompasses a variety of cultures that bear their specific specificity and identity. The present study aims at the digitization of models of national and historical value, applying modern technological means. To achieve the goal, a methodical process is used to optimize the interaction of the different working steps.
\end{abstract}

Keywords: Digitization, photogrammetry, 3D, Belt-buckles

\section{Introduction}

Digitization by photogrammetric measurements and calculations makes it possible to store the data of three-dimensional geometry of models with particular national and historical significance (Georgieva I. (1993), Tachev M. (2012)). This is important both for the preservation of the characteristic geometric features and for the overall storage of the visual parametric data in suitable file formats, which allow restoration, reproduction, re-design and other activities.

The present work is aimed at the study of typical metallic models - belt-buckles, which have an ancient character and are used in the traditional Bulgarian costume and nowadays (Stoeva G o.s., Koleva T. (2014) o.s.). The buckles are characterized by their rich details, the variety of shapes and plots (Magazine "Bulgarka" (2015), NarodniNosii (2018)). They impress with elegance and beauty (Sirakov N., Demirev V., Ilieva D., Ivanov I. (2014), Uchiteli (2016)-o.s., Topalova R.-o.s., Iliev I., Kazakova R., Genova M. (2014)-o.s.). This gives grounds to take the necessary action to preserve the patterns as a national treasure guiding its roots from the very earliest times. The buckles are versatile in terms of their visual characteristics, sizes and materials. Different types of buckles are shown in fig.1.

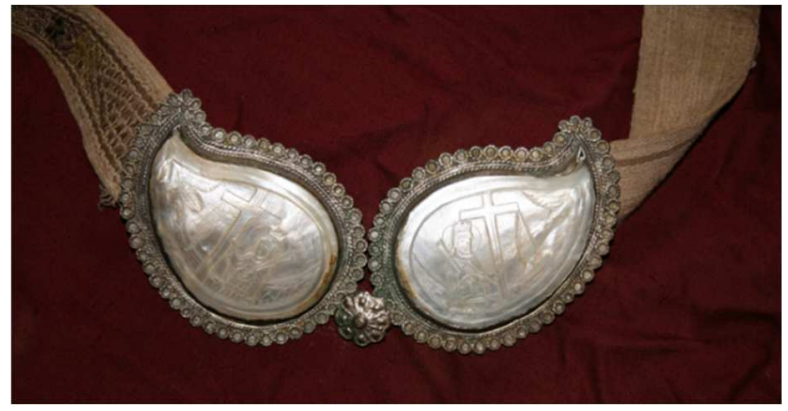

(a)

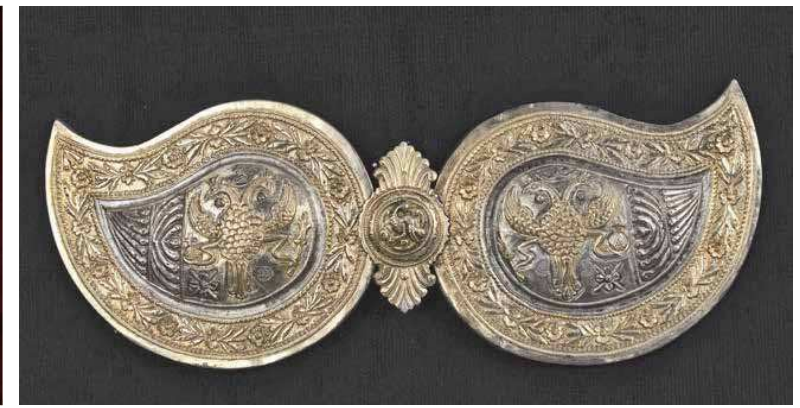

(b) 


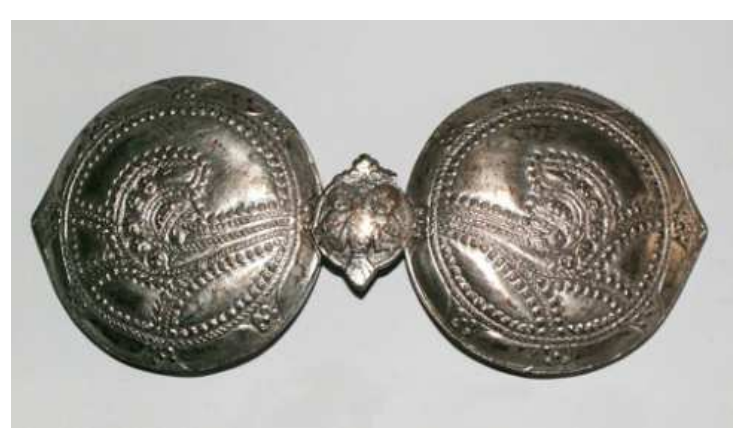

(c)

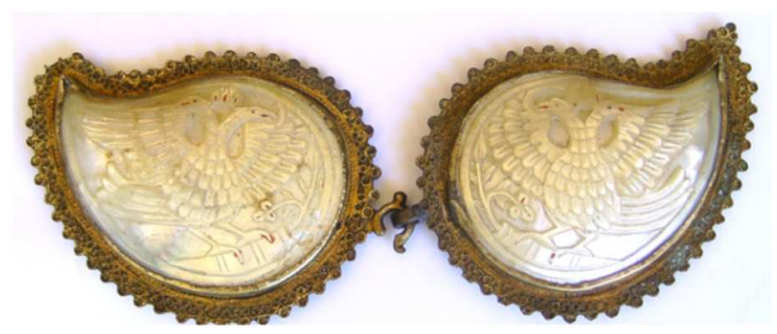

(d)

Fig. 1. Traditional Bulgarian belt buckles: (a) With a cross symbol (Uchiteli (2016)-o.s.); (b) Silver alloy with gold plating with double-headed eagle (Sirakov N., Demirev V., Ilieva D., Ivanov I. (2014)); (c) Brass, round, pointed at one end. With plant motifs and double-headed eagle (Topalova R.-o.s); (d) Silver belt buckles with horn beds, XIX century (Iliev I., Kazakova R., Genova M. (2014)-o.s.)).

One of the appropriate methods for digitizing such models is photogrammetry (Guidi G. *, Gonizzi S., Micoli L.L (2014), Lobanov A. N. (1984), Nazarov A. S. (2006), Obiralov A. I., Limonov A. N., Gavrilova L. A. (2002), Schenk T. (2005), Waas M., Zell D. (2014)). It involves a specific technological process (Dovramadjiev T. (2017), Laakso A. (2016)), where real models by means of capturing apparatus (Kaufman J., Rennie A., Clement M. (2015)). and special software applications (Autodesk MeshMixer - o.s., Autodesk ReCap o.s.), recreate in the virtual space a three dimensional geometry similar to the real. Fig. 2 (Photogrammetry - Metrology process) and fig. 3 (Photogrammetry - Triangulation process) show the conventional principles of realizing the digitalisation of a three-dimensional real model in a virtual one by photogrammetry (Geodetic Systems -o.s, IQLaser -o.s).

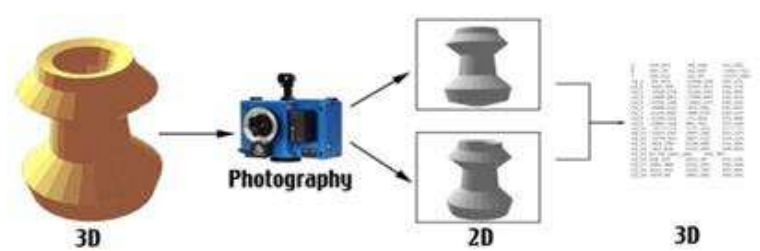

30

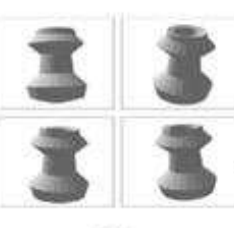

2D

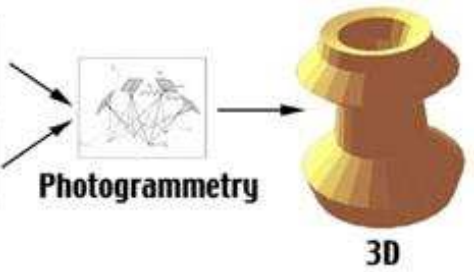

30

Fig. 2. Photogrammetry - Metrology process. Fig. 3. Photogrammetry - Triangulation process.

The quality of the samples and patterns obtained depends on many factors including the choice of a suitable room and / or environment, a working scene, shooting equipment, precision in the setting of parameters and operator definitions, individual work in a design process in computer 3D modeling.

Choosing the photogrammetry has the following advantages over conventional 3D scanning in terms of 3D restoration and recovery of models that have already disappeared and / or destroyed, but there are enough documentary photo materials or videos that can be handled as individual images using specialized software applications that retrieve frames in raster file formats). This is especially important when working with artifacts, objects, and other objects of an ancient character. Considering the ancient character of the buckles (referring to those that were made decades ago and centuries ago), the application of an optimized photogrammetric methodology is a necessity. 


\section{Materials and Methods}

Similar to the models of Figure 1, there are models of belt buckles to be digitized in the present work (Figure 4: (a) Model 1; (b) Model 2 and (c) Model 3).

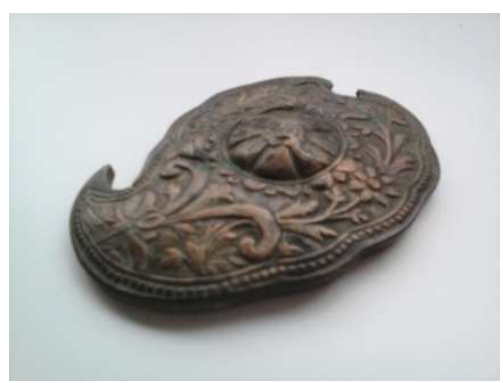

(a)

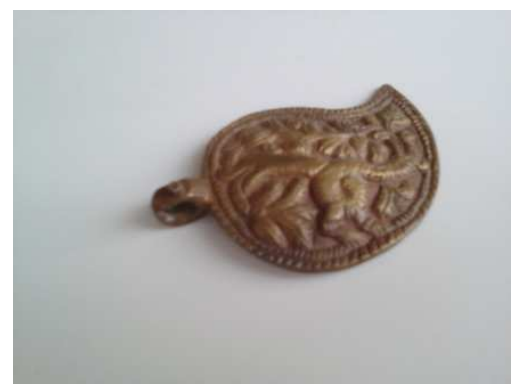

(b)

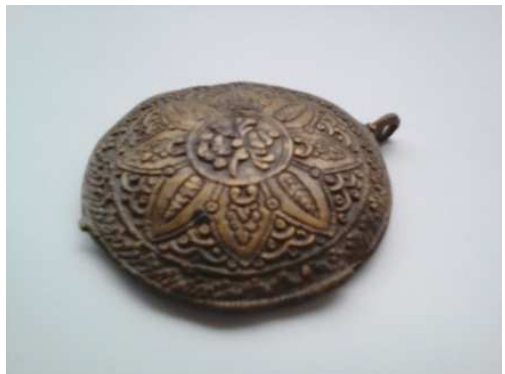

(c)

Fig. 4. Real models of Belt-buckles: (a) Model 1, (b) Model 2 and (c) Model 3.

The performance of the photogrammetric process includes a sequence of stages that are specific in their functionality and conform to the standards set forth in figures 2 and 3 . There are used: shooting equipment, professional program for photogrammetric measurements and calculations, data processing, conversion and storage in suitable file formats. An optimized methodology used in this study is shown in fig. 5

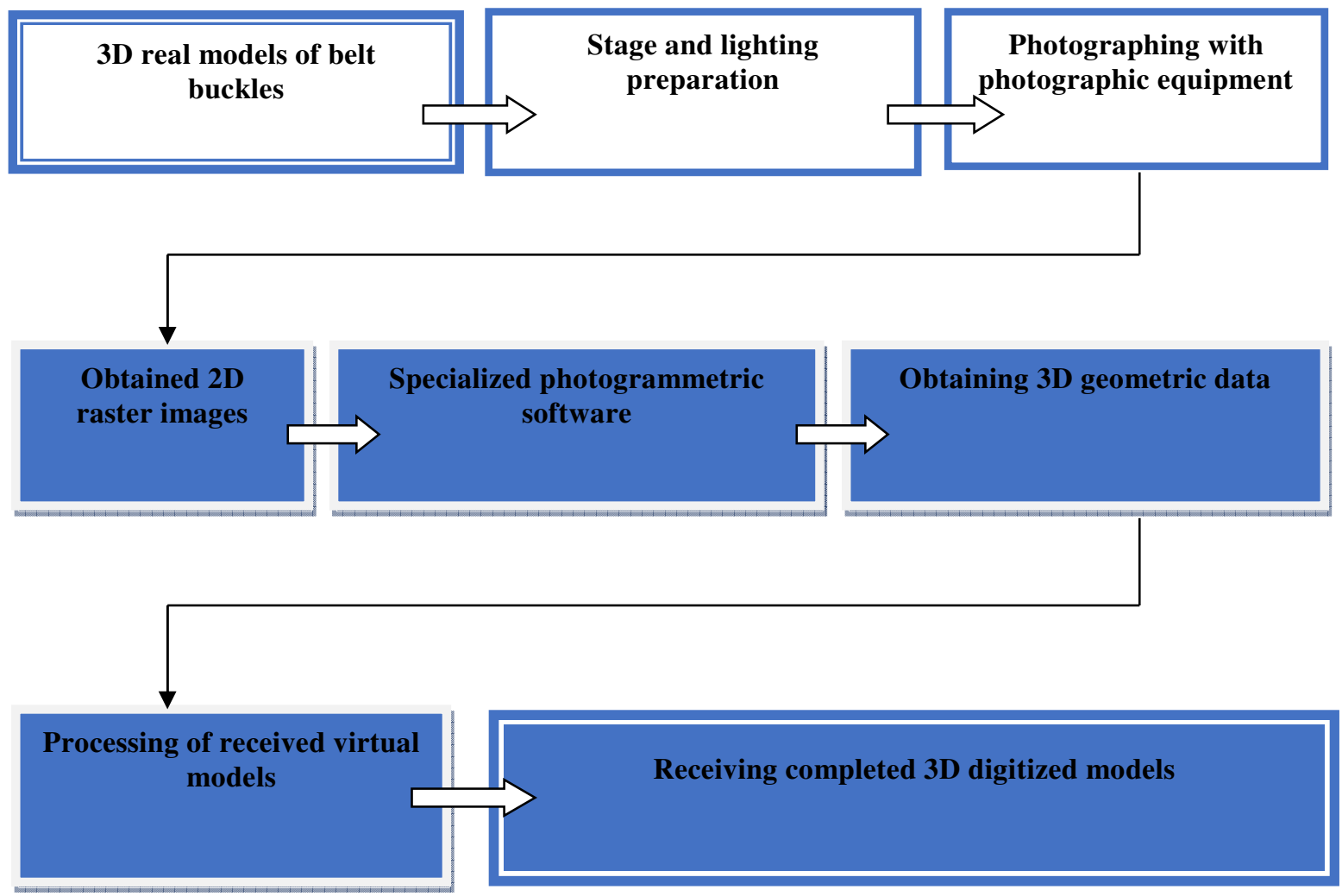

Fig. 5. Optimized photogrammetric methodology. 


\section{Model 1}

In the first model of the belt buckles predominate floral ornaments. The shooting of the real model is done on a white canvas, and in the lens of the camera additional details of the environment, which would affect the received images are avoided 47 photos have been taken and processed in photogrammetric software Autodesk ReCAP (fig. 6).

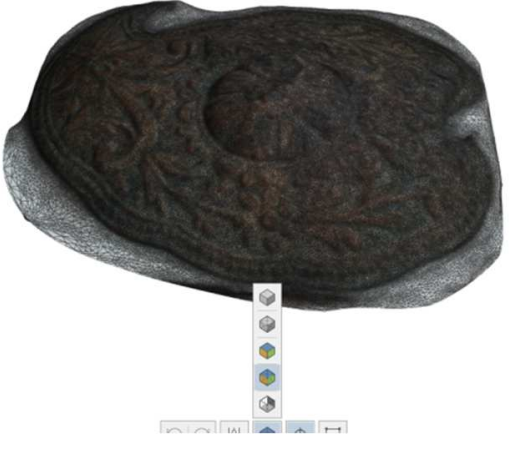

(a)

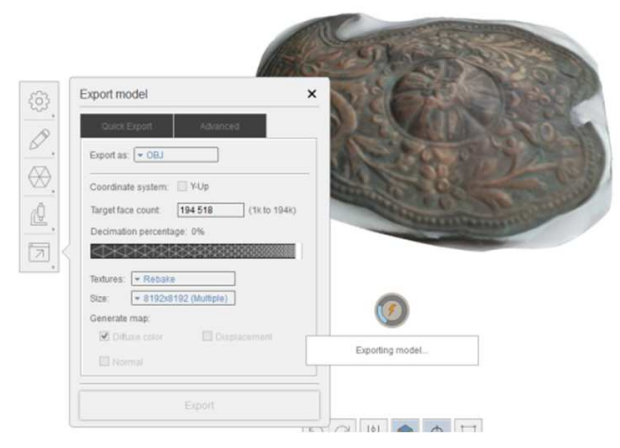

(b)

Fig. 6. Model 1 - Digital model of a belt buckle: (a) In an environment of Autodesk ReCAP with wireframe and texture; (b) Export to file OBJ.

The resulting three-dimensional model can be exported to (*.OBJ or *.STL) for additional processing with specialized sculpting tools in AutoDesk MeshMixer software. These are some of the most used file formats in 3D Rapid Prototyping and 3D Software 3D Modeling. In this case, the OBJ file format is used. The final result due to manual processing of the meshof the model in Autodesk MeshMixer is shown in fig. 7.

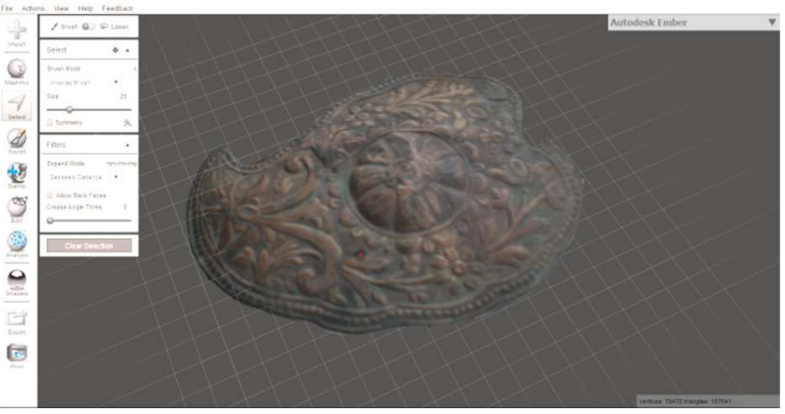

(a)

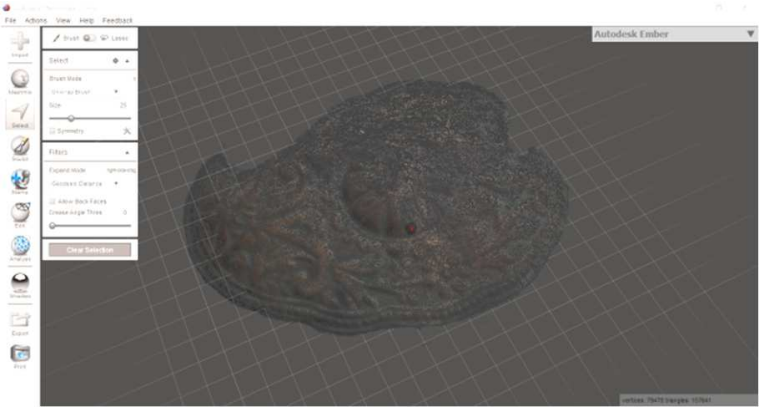

(b)

Fig. 7. Obtained result for model 1. Digital model of the belt buckle in Autodesk MeshMixer environment: (a) with texture; (b) with wireframe and texture.

\section{Model 2}

The second model has floral elements and in the center a figure that resembles a two-headed dragon. The result of Autodesk ReCAP photogrammetry process is shown in fig. 8 . 


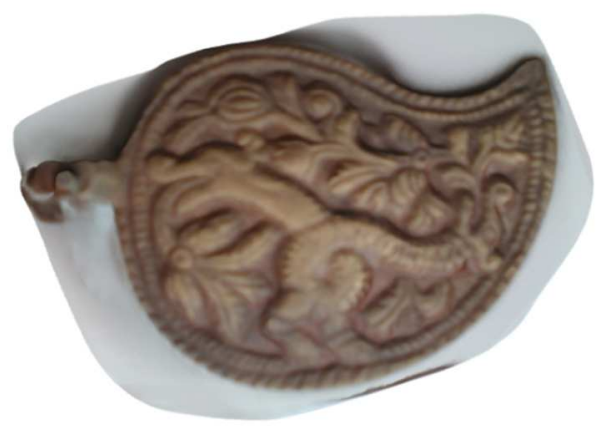

(a)

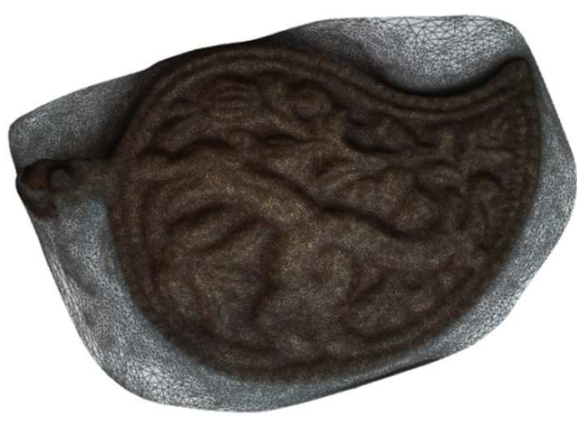

(b)

Fig. 8. Model 2 - Digital model of a belt-buckle in Autodesk ReCAP environment: (a) with texture; (b) with wireframe and texture.

The resulting model in Autodesk ReCAP is exported in a similar way to model 1 and handled with sculpting tools in Autodesk MeshMixer (fig. 9).

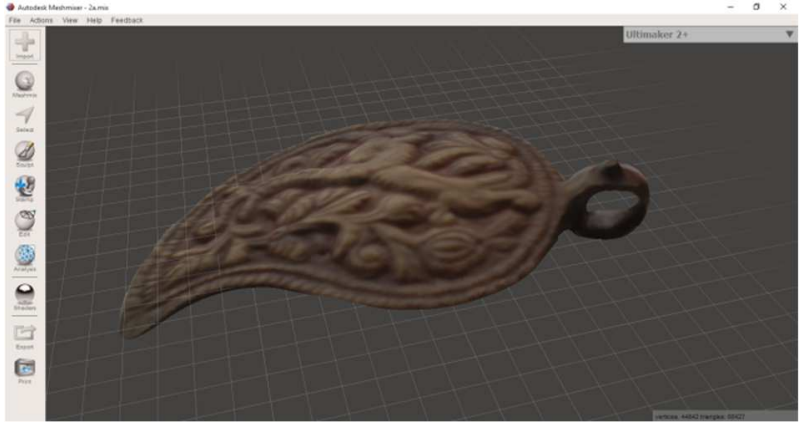

(a)

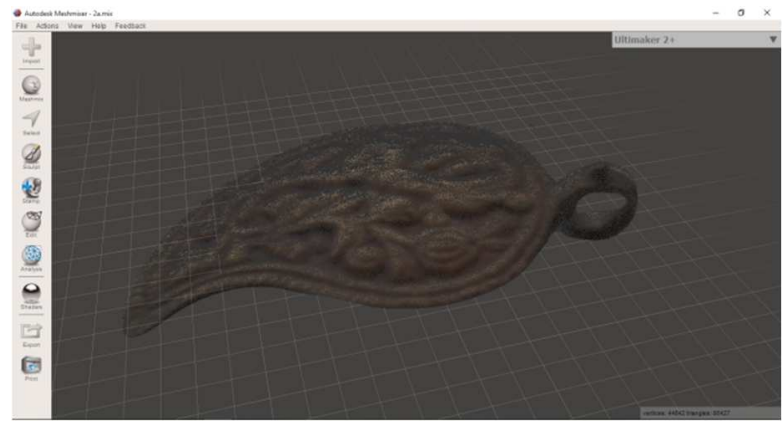

(b)

Fig. 9. Result for model 2. Digital model of the belt buckle in Autodesk MeshMixer environment: (a) with texture; (b) with wireframe and texture.

\section{Model3}

The third model of the belt buckle is in a disc-like shape with floral ornaments. The result of Autodesk ReCAP photogrammetry process is shown in fig. 10.

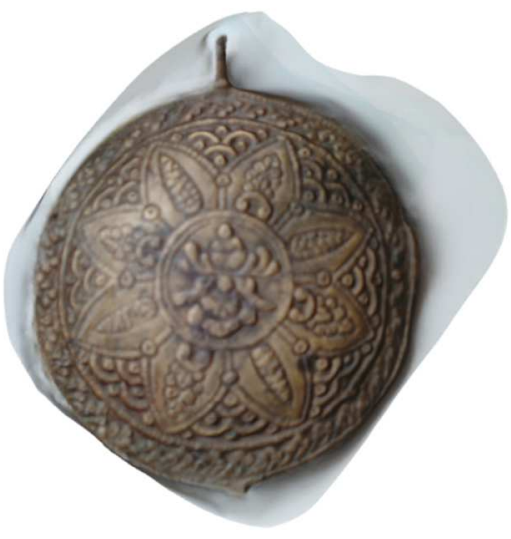

(a)

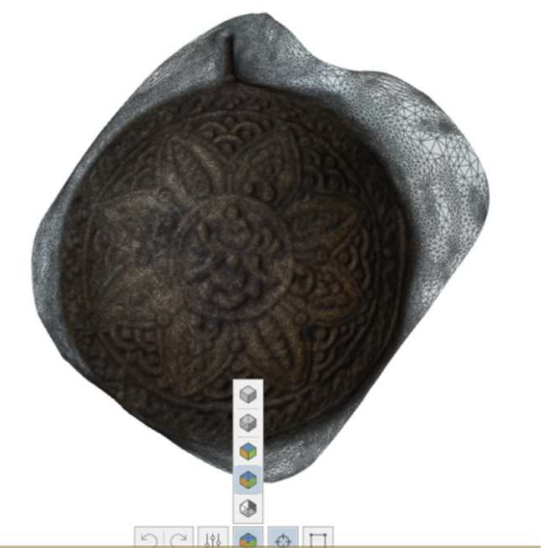

(b)

Fig. 10. Model 3 - Digital model of a belt buckle in Autodesk ReCAP environment: (a) with texture; (b)with wireframe and texture. 
The resulting model in Autodesk ReCAP is exported in a similar way to model 1and model 2 and handled with sculpting tools in Autodesk MeshMixer (fig. 11).

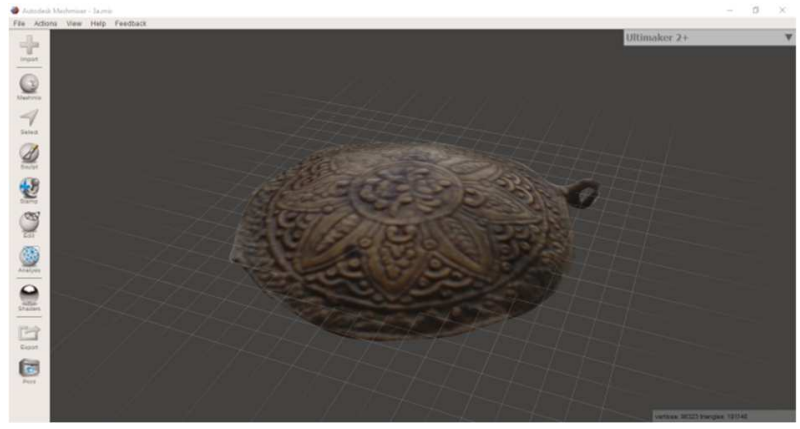

(a)

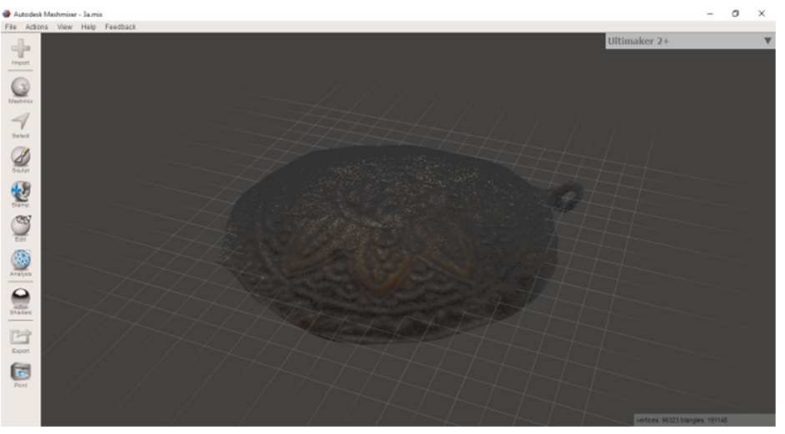

(b)

Fig. 11. Obtained result for model 3. Digital model of a belt buckle in Autodesk MeshMixer environment: (a) with texture; (b) with wireframe and texture.

After optimizing the geometry of the models, they have the following mesh parameters (table 1).

Table 1. Mesh parameters of the models

\begin{tabular}{ccc}
\hline & Vertices & Triangles \\
\hline Model 1 & 78478 & 157641 \\
Model 2 & 44842 & 88427 \\
Model 3 & 96323 & 191148 \\
\hline
\end{tabular}

\section{Conclusion}

As a result of obtaining the original geometric data in a digital format, the models were processed with specialized technical means and results were obtained that have an optimized geometry with respect to the external geometry of the mesh. The final variants are brought into the necessary digital form, which in future processes are used for different forms and activities. Some of them are:

- Creating interactive multimedia presentations;

- Interactive platforms and applications;

- Internet sites;

- Virtual museums;

- Materialisation of real samples through 3D printing;

- Others.

This paper presents a successful process of digitization of models of particular national and historical value, using modern technical means.

Acknowledgments. The described work is a part of project NP -17 2018 / TUV "Study of design possibilities and optimization of computer calculation processes in industrial design practice". 


\section{References}

Dovramadjiev T. (2017). 3D computer processing and improvement of the geometry of received photogrammetric models through photo shooting with one camera. Proceedings of ISCAME 2017, 12-13 October, 2017 Debrecen, Hungary. ISBN 978-963-473-304-1. p. 115 - 122.

Georgieva I. (1993). Bulgarian National Mythology. II Edition. Science and Art, Sofia, ISBN 95402-0077-6.

Guidi, G., Gonizzi, S., \& Micoli, L. (2014). Image pre-processing for optimizing automated photogrammetry performances. In ISPRS Technical Commission V Symposium (Vol. 2, pp. 145-152). ISPRS. doi:10.5194/isprsannals-II-5-145-2014.

Kaufman, J., Rennie, A. E., \& Clement, M. (2015). Single camera photogrammetry for reverse engineering and fabrication of ancient and modern artifacts. Procedia CIRP, 36, 223-229. DOI: 10.1016/j.procir.2015.01.073

Laakso A. (2016). From reality to 3D model. Post production of photogrammetry-based model. LAHTI UNIVERSITY OF APPLIED SCIENCES. a. p. 108

Lobanov A. N. (1984). Photogrammetry. II Edition. Nedra, Moscow. UDK 528.7'(075.8)

Nazarov A. S. (2006). Photogrammetry. Tetra Systems. Russia. UDK 528.711.18 (075.8), BBK 26.12i73; ISBN 985-470-402-5

Obiralov A. I., Limonov A. N., Gavrilova L. A. (2002). Photogrammetry. Koloss. Moscow. UDK 528.7(075.32); ISBN 5-95232-0025-0

Schenk, T. (2005). Introduction to photogrammetry. The Ohio State University, Columbus, 106.

Sirakov N., Demirev V., Ilieva D., Ivanov I. (2014). The Nakit. Regional Historical Museum of Sliven (RIM - Sliven). Museum of NBU (New Bulgarian University). Sofia, ISBN 978-954535-638-5.

Tachev M. (2012). Role of the applied arts in preserving the slavonicidentidy and Bulgarian national idea at the beginning of XX-th century. Work and materials. Moscow, MGU, 21-24.3.2012; ISBN 978-5-211-06356-3

Waas M., Zell D. (2014) Practical 3D photogrammetry for the conservation and documentation of Cultural Heritage. Museen der Stadt Wien - Stadtarchäologie. Proceedings of the 18th International Conference on Cultural Heritage and New Technologies - 2013. ISBN 978-3200-03676-5.

\section{Online sources}

Autodesk MeshMixer software. http://www.meshmixer.com/

Autodesk ReCap software. https://www.autodesk.com/products/recap/overview

Geodetic Systems. Link visited (8.11.2018): https://www.geodetic.com/v-stars/what-isphotogrammetry/ 
Iliev I., Kazakova R., Genova M. (2014). Photo Catalog.Histrorical Museum of Dulgopol (IM Dulgopol) . Link visited (26.10.2018): http://www.dalgopol.org/vid2/168.pdf

IQLaser/ Link visited (8.11.2018): http://www.iqlaser.co.za/files/white_papers/Photogrammetry_basics.pdf

Koleva T. (2014). Tradicionnatadrehanabulgarskatajena. Ekletika. Link visited (26.10.2018): http://eklekti.com/narodnata-tradicionna-nosiya/

Magazine "Bulgarka" (2015). Pafti - moda v antichnostta i vyzrajdaneto. Bulgarka. Link visited (26.10.2018): $\quad$ https://www.bulgarkamagazine.com/пафти-мода-в-античността-ивъзражданет/

NarodniNosii (2018). Nakitiiukrasheniq $\mathrm{v}$ bulgarskitenarodninosii.NarodniNosii. Link visited (26.10.2018): https://narodninosii.bg/blog/nakiti-i-ukrashenia/

Stoeva G. Zapaftiteipoyasite. Cherga. Link visited (26.10.2018): https://cherga.bg/bg/za-paftite-ipoyasite/

Topalova R. Regional Historical Museum of Burgas (RIM Burgas). Link visited (3.11.2018): http://www.burgasmuseums.bg/index.php?page=encdetail\&id=152

Uchiteli (2016). Paftite - simvolnajenstvenosttanabulgarkata. Uchiteli. Link visited (26.10.2018): https://uchiteli.bg/interesting/paftite-simvol-na-zhenstvenostta-na-bylgarkata/2317 